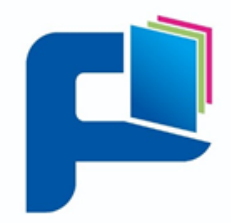

\title{
KUALITAS LAYANAN PENDIDIKAN DI SMK MUHAMMADIYAH BRAJA SELABAH LAMPUNG TIMUR (Studi Kasus Di SMK Muhammdaiyah Braja Selebah)
}

\author{
Yudi Uni Fiandi ${ }^{1}$, Sudirman AM ${ }^{2}$, Marzuki Noor ${ }^{3}$ \\ ${ }^{1}$ SMK Muhammadiyah Braja Selebah \\ ${ }^{23}$ Universitas Muhammadiyah Metro \\ Email: unifiandiy@yahoo.com ${ }^{1}$ \\ sudirman@gmail.com ${ }^{2}$ \\ marzuki@yahoo.com ${ }^{3}$
}

\begin{abstract}
ABSTRAK
Penelitian ini bertujuan untuk mengkaji kualitas pelayanan pendidikan pada Sekolah Menengah Kejuruan Muhammadiyah Braja selebah. Dalam penelitian ini akan di ukur layanan pendidikan berdasarkan standar nasional. Adapun penilaian kualitas layanan pendidikan pada SMK Muhammadiyah Braja Selebah menggunakan penilaian yaitu: layanan sarana prasarana, layanan tenaga pendidik atau guru, dan layanan tenaga kependidikan atau karyawan. Pendekatan yang digunakan dalam penelitian ini adalah pendekatan kualitatif deskriptif. Data kualitatif dianalisis menggunakan model interaktif dengan tahapan yang dimulai dari Pengumpulan Data, reduksi data, penyajian data, dan penarikan kesimpulan. Berdasarkan deskripsi hasil paparan data dan temuan penelitian menunjukkan bahwa kualitas pelayanan pendidikan pada SMK Muhammadiyah Braja Selabah termasuk kategori kurang baik. Dikarenakan masih ada dimensi yang belum berjalan optimal. Dengan demikian diperlukan upaya dari manajemen sekolah untuk memenuhi secara optimal fasilitas-fasilitas fisik sekolah demi terlaksananya pelayanan yang berkualitas, harus meningkatkan kualitas kopetensi guru dan profesioalitas, merumuskan dan menerapkan Prosedur Operasional secara tegas dan konsisten, pengawasan dan pengembangan kompetensi petugas layanan.
\end{abstract}

Kata Kunci: Kualitas Pelayanan tangible, reliability, responsiveness, assurance, empathy

\begin{abstract}
This study aims to assess the quality of educational services at MuhammadiyahVocational High School (SMK) of BrajaSelebah. In this study, education serviceswill be measured based on national standards, as for the assessment of thequality of education services at SMK MuhammadiyahBrajaSelebah usingevaluations, namely: infrastructure services, services for teaching staff, orteachers, and services for educational personnel or employees.The approach used in this research is a descriptive qualitative approach.Qualitative data were analyzed using an interactive model with stages startingfrom data collection, data reduction, data presentation, and concluding.Based on the description of the results of exposure to data and research findings, it shows that the quality of education services at SMK MuhammadiyahBrajaSelabah is in the poor category. Because there are still dimensions that have notrun optimally, it requires efforts from school management to optimally fulfill thephysical facilities of the school for the implementation of quality services. Onemust improve the quality of teacher competence and professionalism, formulateand implement operational procedures firmly, and consistently, supervise anddevelop the capability of service personnel.
\end{abstract}

Keywords: Tangible service quality, reliability, responsiveness, assurance, empathy 


\section{PENDAHULUAN}

Keberadaan lembaga pendidikan (sekolah) sangat dirasa penting oleh seluruh masyarakat. Adanya perubahan pola kehidupan masyarakat yang semakin selektif, masyarakat akan selalu mempertimbangkan tingkat kualitas pelayanan yang diberikan suatu lembaga pendidikan (sekolah) saat memilih sekolah sebagai tempat untuk menuntut ilmu. Masyarakat akan memilih sekolah yang tidak hanya memberikan ilmu saja tetapi juga memberikan pelayanan yang memuaskan sehingga mereka merasa aman dan terjamin saat menuntut ilmu di sekolah. Oleh karena itu, sekolah secara terus - menerus menekankan pada peningkatan kualitas. Berdasarkan hasil pra survey dengan mengunakan metode observasi dan wawancara yang dilakukan siswa dan wali nmurid diperoleh informasi sebagai berikut:

Tabel 1.2 Hasil pra survey dengan cara observasi dan wawancara

\begin{tabular}{l|c|c|c}
\hline \multicolumn{1}{c|}{ Persepsi Layanan Pendidikan } & Harapan & Capaian & Kesenjangan \\
\hline $\begin{array}{l}\text { Kesungguhan Dalam Memebrikan } \\
\text { Layanan }\end{array}$ & $100 \%$ & $45 \%$ & $55 \%$ \\
\hline Tanggung jawab Layanan & $100 \%$ & $45 \%$ & $55 \%$ \\
\hline Keamanan Pelayanan & $100 \%$ & $45 \%$ & $55 \%$ \\
\hline Keadilan Layanan & $100 \%$ & $35 \%$ & $65 \%$ \\
\hline Saranadan prasarana Layanan & $100 \%$ & $30 \%$ & $70 \%$ \\
\hline Suran & & & \\
\hline
\end{tabular}

Sumber:Hasil Prasurvay

Untuk mengetahui tingkat kualitas layanan pendidikan di SMK Muhammadiyah, pada penelitian ini akan dikaji tentang bagaimana kualitas layanan pendidikan SMK Muhammadiyah Braja Selebah dilihat dari kualitas layanan dan tata kelola pelayanan terhadap Mutu pendidikan yang diukur dengan menggunakan penelitian yang koperhensif utuk mengidentifikasi permasalahanpermasalahan ini ada 5 atribut utama yang digunakan untuk mengukur kualitas layanan yaitu (1) Reliability, (2) Responsiveness, (3) Tangibilies (4) Assurance dan (5) Emphaty Berdasarkan dari fenomena di atas, maka diperlukan studi melalui penelitian yang koperhensif utuk meneliti seberapa jauh kualitas layanan pendidikan di sekolah menengah kejuruan muhammadiyah braja selebah lampung timur.

Adapun tujuan penelitian ini adalah :

a. Untuk mengkaji dimensi kualitas layanan pendidikan di SMK Muhammadiyah Braja Selebah Lampung Timur.

b. Untuk mengkaji upaya yang dapat dilakukan untuk meningkatkan kualitas layanan pendidikan di SMK Muhammadiyah Baja Selebah Lampung Timur. 


\section{KAJIAN LITERATUR}

Menurut Wijaya (2011:11) mendefinisikan kualitas sebagi keseluruhan gabungan karakteristik produk dan jasa yang dihasilkan dari pemasaran, rekayasa, produksi, dan pemeliharaaan yang membuat produk dan jasa tersebut dapat digunakan memenuhi harapan pelanggan dan konsumen. Kualitas adalah sesuatu yang diputuskan oleh pelanggan. Artinya, kualitas didasarkan pada pengalaman aktual pelanggan atau konsumen terhadap produk atau jasa yang di ukur berdasarkan persyaratan-persyaratan tersebut. Sedangkan menurut Goetsch dan Davis (dalam Tjiptono, 2008:152) kualitas adalah kondisi dinamis yang berhubungan dengan produk, jasa, sumber daya manusia, proses, dan lingkungan yang melebihi atau memenuhi harapan.

Menurut Kotler (2000:18), pelayanan atau sevice adalah sebuah tindakan atau kegiatan yang dapat ditawarkan oleh suatu pihak kepada pihak lain yang pada dasarnya tidak berwujud dan tidak mengakibatkan kepemilikan apapun. Pengertian yang lebih luas juga disampaikan oleh Daviddow dan Utal dalam Sutopo dan Suryanto (2003:9) bahwa pelayanan merupakan usaha apa saja yang mempertinggi kepuasan pelanggan (whatever enhances customer satisfaction).

Kualitas pelayanan (jasa) adalah tingkat keunggulan yang diharapkan dan pengendalian atas tingkat keunggulan tersebut untuk memenuhi keinginan pelanggan. Dengan demikian ada 2 faktor utama yang mempengaruhi kualitas pelayanan (jasa), yaitu: expected service dan perceived Service. Apabila pelayanan (jasa) yang diterima atau dirasakan (perceived service) sesuai dengan yang diharapkan (expected service), maka kualitas pelayanan (jasa) dipersepsikan baik dan memuaskan. Jika pelayanan (jasa) yang diterima melampaui harapan pelanggan, maka kualitas pelayanan (jasa) dipersepsikan sebagai kualitas yang ideal. Sebaliknya jika pelayanan (jasa) yang di terima lebih rendah daripada yang di harapkan, maka kualitas pelayanan (jasa) dipersepsikan buruk. Maka, baik tidaknya kualitas pelayanan (jasa) tergantung pada penyedia pelayanan (jasa) dalam memenuhi harapan pelanggannya secara konsisten.

Lockhart (2005) dalam Wijaya (2012: 16) memberikan definisi bahwa pemasaran jasa pendidikan adalah suatu cara yang digunakan sekolah untuk memperkenalkan atau mempromosikan kepada siswa, orang tua siswa, karyawan sekolah, dan masyarakat bahwa sekolah merupakan suatu lembaga yang mendedikasikan diri untuk melayani kebutuhan pelanggan jasa pendidikan. Dimensi pokok kualitas jasa yang dikemukakan oleh Parasuraman, Zeithaml dan Berry (1988) dapat diaplikasikan dalam dunia pendidikan yang terdiri dari lima dimensi , yaitu empati (empathy); bukti fisik (tangibles); keandalan (reliability); daya tanggap (responsiveness); dan jaminan (assurance)" (Wijaya, 2012: 23). Kelima dimensi kualitas layanan pendidikan yang dikemukakan oleh Wijaya dapat dijabarkan sebagai berikut: 
1. Empati (Empathy), yaitu sekolah mampu memberikan perhatian yang tulus pribadi kepada pelanggan jasa pendidikan dengan memahami keinginan pelanggan jasa pendidikan. Sekolah juga diharapkan memiliki pengertian dan pengetahuan tentang pelanggan jasa pendidikan, memahami kebutuhan pelanggan jasa pendidikan secara khusus, serta memiliki waktu opeasi jasa pendidikan yang nyaman bagi pelanggan jasa pendidikan.

2. Bukti Fisik (Tangibles), yaitu kemampuan sekolah untuk menunjukkan keberadaan dirinya pada pihak eksternal sekolah, meliputi fasilitas fisik (gedung, gudang, dan lainlain), perlengkapan dan peralatan pendidikan yang digunakan, serta tampilan karyawan sekolah.

3. Keandalan (Relibility), yaitu kemampuan sekolah untuk menyediakan jasa pendidikan sesuai dengan janji secara akurat dan terpercaya. Kinerja sesuai harapan pelanggan jasa pendidikan berupa ketepatan waktu, pelayanan yang seragam untuk setiap pelanggan jasa pendidikan tanpa kesalahan, sikap yang simpatik, dan keakuratan yang tinggi.

4. Daya Tanggap (Responsiveness), yaitu kebijakan untuk membantu serta memberikan jasa pendidikan yang cepat dan tepat kepada pelanggan jasa pendidikan.

5. Jaminan (Assurance), yaitu pengetahuan, kesopansantunan, serta kemampuan karyawan sekolah untuk menumbuhkan rasa percaya pelanggan jasa pendidikan pada sekolah, meliputi komunikasi, kepercayaan, keamanan, kompetensi, dan sopan santun.

\section{METODE PENELITIAN}

Penelitian yang dilakukan penulis adalah jenis penelitian kualitatif. Penelitian kualitatif menurut Sukmadinata, (2010: 69) berpendapat bahwa penelitian kualitatif (qualitative research) adalah suatu penelitian yang ditujukan untuk mendeskripsikan dan menganalisis fenomena, peristiwa, aktivitas sosial, sikap, kepercayaan, persepsi, pemikiran orang secara individual maupun kelompok.

Menurut Haris Herdiansyah (2012:12) Berpendapat bahwa pendekatan kualitatif adalah suatu penelitian ilmiah yang bertujuan untuk memahami suatu fenomena dalam konteks sosial secara alamiah dengan mengedepankan proses interaksi komunikasi yang mendalam antara peneliti dengan fenomena yang diteliti. Pendekatan yang dipakai dalam penelitian ini menggunakan pendekatan kualitatif deskriptif yaitu suatu penelitian yang bermaksud memahami fenomena tentang apa yang dialami oleh subjek penelitian misalnya perilaku, persepsi, motivasi, tindakan, dan lain-lain secara holistik dan dengan cara deskripsi dalam bentuk kata-kata dan bahasa pada suatu konteks khusus yang alamiah serta dengan memanfaatkan berbagai metode alamiah. (Tohirin, 2012:3) Dengan perkataan lain, pendekatan deskriptif adalah suatu metode penelitian yang melihat 
obyek/kondisi, gambaran, secara sistematis, faktual, dan akurat mengenai fakta yang diselidiki dan hasilnya dapat dipergunakan untuk pengambilan keputusan di masa mendatang. Pendekatan deskriptif juga bertujuan untuk mendapatkan uraian mendalam tentang ucapan, tulisan, dan tingkah laku yang dapat diamati dari suatu individu, kelompok, masyarakat maupun organisasi dalam setting tertentu yang dikaji dari sudut pandang yang komprehensif.

Kehadiran dan keterlibatan peneliti di lapangan sangat diutamakan dalam penelitian kualitatif, karena peneliti merupakan instrument penelitian utama yang harus hadir di lapangan untuk mengumpulkan data yang diperlukan dalam situasi yang sesungguhnya (Moleong, 2008:87).

Data yang dikumpulkan melalui penelitian ini adalah data yang sesuai dengan fokus penelitian. Dalam penelitian ini data dibedakan menjadi dua jenis, data primer dan data sekunder (Moleong, 2017:157). Teknik pengumpulan data adalah suatu cara yang digunakan untuk mendapatkan data dalam penelitian. Teknik pengumpulan data yang digunakan adalah teknik field research yaitu penulis terjun langsung ke lapangan untuk memperoleh data yang diperlukan, sedang metode observasi dan wawancara. data kualitatif dianalisis menggunakan metode Miles dan Huberman dengan tahapan yang dimulai dari reduksi data, penyajian data, dan penarikan kesimpulan.

Hasil analisis data disusun setelah melalui langkah melengkapi dan menyempurnakan dari data-data yang diperoleh dari tahap-tahap interview, pengamatan dan dokumentasi. Setelah penyusunan hasil analisis dilakukan, maka teknik terakhir adalah menyusun cara menyajikan dan mempertanggung jawabkan hasil penelitian deskriptif. Setelah data dikumpulkan, kemudian disusun rumusan pengertian secara singkat berupa pokok-pokok temuan yang disebut dengan reduksi data. Langkah berikutnya adalah penyusunan sajian data yang berupa cerita sistematis. Dari itu kemudian ditarik kesimpulan. Jika belum tepat kesimpulannya kemudian dicek lagi data yang dikumpulkan atau mencari data lagi guna mendapat data yang akurat dan dapat dipertanggung jawabkan. Data tersebut kemudian ditarik kesimpulan.

\section{HASIL PEMBAHASAN}

Berdasarkan hasil analisis penelitian dari temuan penelitian yang dipeoleh dengan cara wawancara dan observasi maka hasil penelitian untuk masingmasing dimensi adalah sebagai berikut:

\section{a) Tangible}

Hasil analisi data kuantitatif pada indikator tangibles menunjukkan hasil yang sama yaitu sebagian besar informan berpendapat bahwa kualitas pelayanan pendidikan pada SMK Muhammadiyah Braja Selebah termasuk dalam kategori kurang baik Hal ini sejalan dengan pendapat Zaithaml, Parasurahman \& Berry (1992:1-12), bahwa kualitas pelayanan yang dilihat dari fasilitas fisik yang kasat 
mata merupakan salah satu indikator yang menentukan tingkat kualitas pelayanan publik yang ideal. Fasilitas yang dimiliki sekolah kurang lengkap dapat mempengaruhi kegiatan pelayanan dan dapat berimplikasi langsung terhadap kualitas pelayanan secara keseluruhan.

\section{b.) Reliability}

Hasil yang diperoleh diinformasikan melalui tanggapan masing- masing informan yang menginginkan agar dilakukan perbaikan. Pada indikator kualitas layanan publik (reliability) karena dinilai kurang. Hasil yang diperoleh pada SMK Muhammadiyah Braja Selebah yang mencerminkan indikator kualitas layanan publik (reliability) tersebut dinilai kurang baik. Sejalan dengan pendapat (Wijaya, 2012: 23). yang menyatakan bahwa: Keandalan (Relibility), yaitu kemampuan sekolah untuk menyediakan jasa pendidikan sesuai dengan janji secara akurat dan terpercaya. Kinerja sesuai harapan pelanggan jasa pendidikan berupa ketepatan waktu, pelayanan yang seragam untuk setiap pelanggan jasa pendidikan tanpa kesalahan, sikap yang simpatik, dan keakuratan yang tinggi. SMK Muhammadiyah Braja Selebah belum dapat mencapat kualitas pelayanan yang baik pada indikator ini.

\section{c.) Responsiviness}

Berdasarkan deskeripsi hasil penelitian yang diperoleh diinformasikan melalui tanggapan masing- masing informan yang menginginkan agar dilakukan perbaikan pada indikator metode pembelajaran pada dimensi kualitas layanan (responsiviness) karena dinilai kurang baik. Menurut (Wijaya, 2012: 23) Daya Tanggap (Responsiveness), yaitu kebijakan untuk membantu serta memberikan jasa pendidikan yang cepat dan tepat kepada pelanggan jasa pendidikan. Kesanggupan dan penyediaan pelayanan yang berkualitas tergantung dari kinerja suatu organisasi/ sekolah

\section{d.)Assurance}

Dari hasil deskripsi hasil penelitian yang diperoleh diinformasikan melalui tanggapan masing- masing informan yang menginginkan agar melakukan perbaikan pada indikator kualitas layanan (assurance) karena dinilai kurang baik. Sesuai dengan pendapat (Wijaya, 2012: 23) menyatakan bahwa Jaminan (assurance), yaitu pengetahuan, kesopansantunan, serta kemampuan karyawan sekolah untuk menumbuhkan rasa percaya pelanggan jasa pendidikan pada sekolah, meliputi komunikasi, kepercayaan, keamanan, kompetensi, dan sopan santun. dimensi assurance sangat menentukan berjalannya kegiatan pelayanan dan dapat memberikan dampak terhadap indikator yang lainnya.

\section{d.) Emphaty}

Dari deskripsi hasil penelitian menunjukkan bahwa semua indikator dalam dimensi emphaty dalam pelayanan publik di SMK Muhammadiyah Braja Selebah ini sudah baik. Sejalan dengan pendapat (Wijaya, 2012: 23) bahwa Empati (Empathy), yaitu sekolah mampu memberikan perhatian yang tulus pribadi kepada pelanggan jasa pendidikan dengan memahami keinginan pelanggan jasa 
pendidikan. Sekolah juga diharapkan memiliki pengertian dan pengetahuan tentang pelanggan jasa pendidikan, memahami kebutuhan pelanggan jasa pendidikan secara khusus, serta memiliki waktu opeasi jasa pendidikan yang nyaman bagi pelanggan jasa pendidikan.

\section{KESIMPULAN}

Hasil penelitian ini dapat memberikan kontribusi bagi pengembangan ilmu administrasi publik khususnya yang terkait dengan kualitas pelayanan publik pada sektor pendidikan yaitu SMK Muhammadiyah Braja Selebah. Penelitian ini telah mampu membuktikan bahwa dimensi kualitas pelayanan publik yang terdiri dari 5 dimensi (tangible, reliability, responsiveness, assurance, dan emphaty).

\section{DAFTAR PUSTAKA.}

Agani, Dimas Purwa., Elvira Azis. (2021). Pengaruh Kualitas Informasi, Kualitas Sistem, Kualitas Layanan terhadap Kepuasan Pengguna Aplikasi SPPD. EProceeding of Management. Vol.8, No.1 Februari 2021. Hal 67-72.

Haris Herdiansyah. (2012). Metodologi Penelitian Kualitatif untuk Ilmu-ilmu Sosial.Jakarta: Salemba Humanika.

Irma, Shanty. (2021). Kualitas Layanan Dalam Pelaksanaan Pelatihan PNS. Jurnal Manajemen Perbankan Keuangan Nitro. Vol 4 No 1 Hal Jan 2021 Hal 9-16.

Kotler, Philip \& Armstrong, Garry. (2008). Prinsip-prinsip Pemasaran, Jilid 1. Jakarta: Erlangga.

Kotler, P., \& Keller, K. L. (2006). Marketing Management (11 thed). New Jessey: Pearson Education, Ing Upper Saddle River.

Moleong. J. Lexy. (2017). Metode Penelitian Kualitaif Edisi Revisi. Bandung: Rosdakarya.

Martono, Samuel. (2021). Evaluasi Mutu Layanan Pendidikan Tinggi (Studi Pada Program Akuntansi Fakultas Ekonomika Dan Bisnis Universitas Kristen Satya Wacana). Jurnal JEMAP. Vol 4 No Hal 28-51.

Peraturan Pemerintah Nomor 19 Tahun 2005 tentang Standar Nasional Pendidikan (Lembaran Negara Republik Indonesia Tahun 2005 Nomor 41, Tambahan Lembaran Negara Republik Indonesia Nomor 4496).

Ratminto, dan Atik Winarsih. (2007). Manajemen Pelayanan, Yogyakarta: Pustaka.

Sanjaya, Wina. (2013). Penelitian pendidikan, jenis, metode dan prosedur, Jakarta: Kencana Prenada Media Group.

Sutama. (2010). Metode penelitian kuantitatif, kualitatif, PTK, $R \& D$, Surakarta: 
Fairuz Media.

Tjiptono, Fandy. (2008). Service Management, Edisi Kedua. Yogyakarta: AndiOfset.

Tohirin. (2012). Metode penelitian Kualitatif dalam Pendidikan dan imbingan Konseling, Jakarta : PT Raja Grafindo Persada.

Undang-Undang Republik Indonesia Nomor 20 Tahun 2003 Tentang Sistem Pendidikan Nasional.

Wijaya, Tony. (2018). Manajemen Kualitas Jasa. Jakarta: PT Indeks. 